\title{
Abordagens conceituais e aplicativas da mediação nos serviços de informação
}

\author{
Conceptual and applicative approaches of mediation in information services
}

\begin{abstract}
Jonathas Luiz Carvalho Silva Doutor em Ciência da Informação pela Universidade Federal da Bahia - UFBA. Professor do Curso de Graduação e do Mestrado Profissional em Biblioteconomia da Universidade Federal do Cariri - UFCA. Coordenador do Programa de Pós-Graduação em Biblioteconomia (PPGB) - UFCA. E-mail: jonathascarvalhos@yahoo.com.br
\end{abstract}

Maria Giovanna Guedes Farias Doutora em Ciência da Informação pela Universidade Federal da Bahia - UFBA. Professora do Departamento de Ciências da Informação e Programa de Pós-Graduação em Ciência da Informação da Universidade Federal do Ceará - UFC. E-mail: mgiovannaguedes@gmail.com

\section{Resumo}

Apresenta a mediação da informação como um campo profícuo de estudos e práticas profissionais no campo da Ciência da Informação (CI) e no espectro biblioteconômico-informacional, relacionado a diversos outros conceitos como serviços de informação, competências em informação, produtos de informação, tecnologias de informação, gestão da informação. Objetiva abordar as perspectivas teórico-conceituais e tipológicas da mediação da informação, estabelecendo intercorrências com os serviços de informação, contemplando aplicações mútuas no desiderato da mediação implícita e explícita. Utiliza como percurso metodológico a pesquisa bibliográfica, estabelecendo diálogo com obras diversas como livros e artigos sobre as temáticas "mediação" e "serviços de informação". Os resultados demonstram que há várias possibilidades de aplicação da mediação implícita e explícita, tanto para a fundamentação das pesquisas sobre mediação da informação, quanto para práticas profissionais em ambientes de informação. Concluise que as relações entre mediação e serviços de informação demonstram o amplo caráter técnico, pedagógico e institucional na CI e nas práticas profissionais nos ambientes de informação.

Palavras-chave: Mediação da informação. Serviços de informação. Mediação implícita. Mediação explícita.

\begin{abstract}
It displays the mediation of information as a fruitful field of study and professional practice in the field of Information Science (IS) and in the informational-librarianship spectrum, related to several other concepts such as information services, information skills, information products, technologies information, information management. Aims to address the theoretical and conceptual and typological perspectives of information mediation, establishing complications with information services, considering investments in mutual desideratum of implicit and explicit mediation. Use as a methodological approach a bibliographic research, establishing dialogue with various literary works such as books and articles on the themes "mediation" and "information services". The results show that there are several possibilities for using implicit and explicit mediation, both for reasons of research on information mediation, and for professional practices in information environments. It was concluded that the relationship between mediation and information services demonstrate the broad technical, educational and institutional character in the IS and in the professional practices in information environments.
\end{abstract}

Keywords: Mediation of information. Information services. Implicit mediation. Explicit mediation.

InCID: R. Ci. Inf. e Doc., Ribeirão Preto, v. 8, n. 2, p. 106-123, set. 2017/fev. 2018.

DOI: 10.11606/issn.2178-2075.v8i2p106-123 


\section{Introdução}

O conceito de mediação se propagou em diversas áreas do conhecimento, como: direito, educação e comunicação, recebendo diversas aplicações conceituais dessas áreas. $\mathrm{Na}$ Biblioteconomia e na Ciência da Informação (CI), a mediação da informação tem sido objeto de estudo de diversas pesquisas perpassando várias disciplinas nessas áreas, por seu caráter transversal.

Do latim mediatione que designa originalmente intervenção humana entre duas partes, ação de dividir em dois ou estar no meio, o conceito de mediação foi tomado por diferentes perspectivas, conforme Rasteli e Cavalcante (2013), indicando ideias de interveniência, relação, conjugação, religação, ponte ou elo estabelecido nas relações humanas, por meio de um elemento mediador.

A mediação da informação é vista por Silva e Silva (2012) como um fio condutor que liga processos, e aproxima constructos de processamentos técnicos aos procedimentos de ação social e pedagógica. A noção de conexão favorecida pela mediação, também está nas reflexões de Almeida (2009), as quais apontam a mediação está ligada às conexões estabelecidas entre as ações sociais e as motivações (individuais/coletivas). Podendo ser vistas como sinônimo de processos de interlocução e/ou interação entre os membros de uma comunidade, por meio dos quais, os laços de sociabilidade são estabelecidos e alimentados.

Desse modo, a mediação da informação surge como um campo profícuo de estudos e práticas profissionais no campo da CI e no espectro biblioteconômico-informacional, relacionado a diversos outros conceitos como serviços de informação, competências em informação, produtos de informação, tecnologias de informação, gestão da informação etc.

Como ponto de partida para a produção deste artigo delineou-se a seguinte questão: quais as relações entre mediação e serviços de informação e quais possíveis aplicações da mediação no contexto dos serviços de informação, especialmente no que tange as perspectivas implícita e explícita? O objetivo é abordar as perspectivas teórico-conceituais e tipológicas da mediação da informação, estabelecendo intercorrências com os serviços de informação, contemplando aplicações mútuas no desiderato da mediação implícita e explícita. 
A metodologia utilizada sustenta-se por uma pesquisa bibliográfica que busca, através do diálogo com bibliografias diversas como livros e artigos sobre as temáticas "mediação" e "serviços de informação", tanto de forma peculiar, quanto de forma associativa, visando conceber uma interlocução teórico-conceitual e de aplicação que dimensione as múltiplas relações entre ambas às terminologias.

O tema desta pesquisa foi desenvolvido contemplando as seguintes razões: a) acadêmicocientífica: concernente ao estímulo de novas vertentes de pesquisas e aplicações teóricometodológicas sobre as relações entre mediação e serviços de informação; b) filosófica: atinente à identificação e análise sobre percepções teórico-conceituais sobre mediação da informação, mas não como um conceito isolado, e sim como conceito associativo a diversos outros conceitos/terminologias como serviços de informação.

\section{Abordagens teórico-conceituais e tipológicas sobre mediação da informação}

Optou-se por tratar inicialmente, da abordagem conceitual epistemológica da mediação nas áreas da Educação, Ciência da Informação e Comunicação. Na abordagem da mediação na educação, como explicam Santos e Rezende (2002), a mediação pedagógica se realiza pelo diálogo, pela troca de experiências e debate de questões de forma investigadora, pelo auxílio à seleção, organização e avaliação de informações, cooperação entre os participantes, pelo desenvolvimento de uma ação educativa que promova a construção ativa.

O sentido da mediação na comunicação constitui, conforme Lamizet (1999), as formas culturais de pertença e de sociabilidade, dando-lhes as formas e os usos pelos quais os atores da sociabilidade apropriam-se dos objetos constitutivos da cultura. Em relação à abordagem da mediação na CI, há algumas concepções empreendidas pelos estudiosos considerando conceitos, tipologias e aplicações mediacionais no âmbito da informação, tais como Almeida Júnior (2008), Malheiro (2009) e Silva (2015).

Iniciando por Almeida Júnior (2008, p. 4) a mediação da informação é dividida em implícita e explícita, sendo que a primeira ocorre nos "espaços dos equipamentos informacionais em que as ações são desenvolvidas sem a presença física e imediata dos usuários. Nesses espaços [...] estão a seleção, o armazenamento e o processamento da informação". Já a segunda acontece nos ambientes 
onde a presença do "usuário é inevitável, é condição sine qua non para sua existência, mesmo que tal presença não seja física, como, por exemplo, nos acessos à distância”.

A tipologia indicada denota que a mediação da informação é um processo encadeado e articulado que envolve tanto questões pedagógicas (mediação explícita), quanto questões técnicas (mediação implícita), considerando que ambas se complementam num continnum de ação de interferência indireta e/ou direta junto à comunidade de usuários, respectivamente.

Em seguida, Malheiro (2009) compreende que a noção da mediação da informação está inserida no contexto do paradigma custodial e pós-custodial. A mediação custodial ou patrimonialista/tecnicista é visualizada como uma concepção de mediação passiva e até "negativa", porque é contrária ao utilizador e a prioridade estava em guardar patrimônio cultural incorporado e acumulado, não no acesso ou na difusão plena. E a mediação pós-custodial e informacional, a qual configura-se como uma multi-mediação, ou seja, a prevalência de uma pluralidade de articulações e de interações centradas na coleta/produção, na organização e na promoção do acesso à informação.

Pensando na tipologia da mediação, pode-se focar nos tipos de mediação pós-custodial, quais sejam:

a) Institucional: Enquadra-se dentro das tradicionais instituições culturais, como Bibliotecas e Arquivos. É exercida pelos mediadores especializados: bibliotecários e arquivistas.

b) Distribuída e/ou partilhada: Ocorre em certos tipos de serviços e mídias digitais pertencentes a entidades coletivas e a indivíduos, em que há mediadores que localizam, digitalizam, selecionam e disponibilizam conteúdos.

c) Cumulativa: À medida que se inovam e expandem mais as possibilidades tecnológicas (novas soluções e produtos), o papel do produtor e do usuário cresce enormemente, desenvolvendo um tipo de mediação cumulativa. (MALHEIRO, 2009).

A mediação da informação em Malheiro (2009) possui um conjunto de dimensões e potencialidades para o desenvolvimento técnico-científico, pedagógico e de aplicação profissional. Primeiramente, há uma dimensão histórica em virtude de que os paradigmas custodial e póscustodial indicam um modus operandi de práticas mediacionais desde o século XIX até o século 
XXI. Vale destacar que a mediação custodial e pós-custodial coexistem no século XXI, mas como fenômenos que conflitam entre si. A mediação pós-custodial é a grande referência de atuação para o século XXI, no campo da Ciência da Informação pelo seu caráter plural e amplamente focalizado, na perspectiva dos sujeitos e na construção crítico-criativa das práticas informacionais.

Já em Silva (2015, p. 105), a mediação da informação é estabelecida por três tipos fundantes, a saber:

a) mediação técnica da informação - concerne as ações de organização, representação da informação envidadas pelo profissional da informação estimulando o uso da informação, seja em ambiente físico ou virtual. Por exemplo, a elaboração de catálogos, interação por e-mail e/ou redes sociais do acervo do centro de informação, entre outros;

b) mediação pedagógica da informação - consiste na condução dos procedimentos e heurísticas a serem utilizadas no processo de mediação. Para tanto, é fundamental um olhar constante nos estudos de usuários contemplando questões relativas ao uso do acervo, das condições tecnológicas, do serviço, das questões de pessoal e avaliação da atuação do centro de informação de forma geral buscando uma aproximação com a comunidade, assim como promovendo autonomia para que o usuário tenha condições de escolha para apreensão e apropriação da informação;

c) mediação institucional da informação - está relacionada aos procedimentos de como o profissional da informação irá buscar recursos (financeiros, pessoais, equipamentos, acervo, instrumentos tecnológicos, etc.), seja dentro ou fora da instituição que o centro de informação está inserido para concretizar suas ações e interferências, assim como promover sua sustentabilidade.

Os tipos de mediação apresentados possuem um conjunto de características entre si. A primeira é de contradição na medida em que há o foco mais intenso em um tipo de mediação em detrimento das demais. Por exemplo, o foco demasiado na mediação técnica relega a um plano inferior a mediação pedagógica e institucional. O segundo é de complementaridade. Quando se pensa a mediação a partir do aspecto institucional a tendência é de que mediação técnica e mediação pedagógica sejam contempladas dependendo das condições oferecidas/conquistadas na mediação institucional e dependendo do foco da equipe que medeia a informação. O terceiro e principal foco 
é o de interdependência. As três mediações podem apresentar contradições e complementos, mas a lógica mais proficiente é a de que são interligadas como atividades holísticas e estratégicas no sentido de que a mediação da informação precisa do institucional para se estabelecer estrutural e gerencialmente, além do técnico e pedagógico para se estabelecer no caráter social e pragmático dos sujeitos (comunidade de usuários) envolvidos na mediação da informação.

\section{Relações conceituais entre mediação e serviços de informação}

O serviço de informação é considerado por Rozados (2004) como uma atividade destinada à identificação, aquisição, processamento e transmissão de informação e ao seu fornecimento, se configurando como todo processo de auxílio ao usuário na busca de informação ou na satisfação de suas necessidades informacionais.

Almeida Júnior (2009), a mediação da informação perpassa todos os serviços relacionados com o tratamento e a disseminação da informação, caracterizando-se como um processo implícito de mediação, na medida em que o usuário não está presente, embora ele seja o alvo de todo este trabalho de organização do conhecimento.

A biblioteca, conforme Varela, Barbosa e Farias (2014), como um canal de transmissão de conhecimento e um aparato educativo-cultural, traz em sua natureza intrínseca a função mediadora. A premissa básica que orienta sua estruturação e funcionamento - reunir, organizar e disseminar a informação - visa atender ao usuário em suas necessidades de conhecimento. Ainda, conforme as autoras, as atividades-meio, aquelas que processam, organizam a informação e preparam os instrumentos de busca e recuperação, são as que vão propiciar a mediação explicita. Envolvendo o bibliotecário, recursos e sistemas informacionais e o usuário; e as atividades-fim, a referência e a disseminação da informação, com a missão de dialogar diretamente com o usuário, hoje no modo presencial ou virtual.

A mediação entre sujeitos também significa permitir às pessoas fazer conexões, como explica Kuhlthau (1993), mover-se do concreto ao abstrato, reconhecer a necessidade de saber mais, estudar mais profundamente e obter maior compreensão. É fundamental por se tratar da intervenção humana para assistir a busca de informação e aprendizagem, a partir do acesso à informação e uso.

InCID: R. Ci. Inf. e Doc., Ribeirão Preto, v. 8, n. 2, p. 106-123, set. 2017/fev. 2018. 
Para Varela (2007), o mediador é uma figura humana que no processo de organização do seu saber, recorre ao seu repertório intelectual, social, ideológico e afetivo. O mediado recebe e particulariza a informação por meio de seu próprio repertório, constituído por seus conhecimentos prévios, por suas predisposições com relação ao conteúdo e ao próprio mediador. O profissional da informação, a partir da consciência de interferência, segundo Almeida Júnior (2008), é entendido em outro estrato profissional, o daqueles que fazem história, são sujeitos na sociedade e participam efetivamente da construção do destino da humanidade. É com a consciência de que interfere, de que se realiza como profissional na relação com o usuário é que a democracia da informação poderá se concretizar.

A ideia de neutralidade, tanto do mediador quanto do processo de mediação, torna-se claramente inapropriada. O momento da relação/interação profissional da informação x usuário é estruturado não como algo estanque. O momento em que se concretiza não é um recorte de tempo estático e dissociado de seu entorno. Ao contrário: resulta da relação dos sujeitos com o mundo. (ALMEIDA JÚNIOR, 2009).

Destarte, as relações entre mediação e serviços de informação residem em uma mutualidade, no sentido de que os serviços de informação se constituem práticas concretas e dinamizam as perspectivas de mediação, enquanto a mediação dá um sentido lógico, estratégico, técnico, pedagógico e institucional aos serviços de informação. No entanto, essas relações envolvem um conjunto de aspectos complexos de cunho paradigmático e temático-aplicativo, conforme revela o quadro a seguir: 
Quadro 1 - Relações entre mediação e serviços de informação

\begin{tabular}{|c|c|}
\hline Relações paradigmáticas & Relações temático-aplicativas \\
\hline $\begin{array}{l}\text { Positivista - está focalizada no viés sistemático e } \\
\text { regulador que tem como prioridade ditar normas para } \\
\text { o acesso à informação, seja no âmbito da } \\
\text { organização/representação da informação, seja no } \\
\text { âmbito da proposição dos serviços que devem ser } \\
\text { oferecidos. Essa mediação positivista da informação } \\
\text { incide sobre a perspectiva de conceber o controle, } \\
\text { previsibilidade e certeza da informação a ser utilizada } \\
\text { pelo usuário da informação, sem considerar de forma } \\
\text { mais ampla seus contextos históricos, cognitivos e } \\
\text { sociais. }\end{array}$ & $\begin{array}{l}\text { Apropriação da informação - para } \\
\text { que a mediação da informação se } \\
\text { constitua como processo é necessário a } \\
\text { consecução de serviços de informação } \\
\text { que permitam a apropriação pelos } \\
\text { usuários. A apropriação é vista como } \\
\text { uma resultante da atividade } \\
\text { mediacional através da elaboração, } \\
\text { oferecimento e execução dos serviços } \\
\text { de informação. }\end{array}$ \\
\hline $\begin{array}{l}\text { Funcionalista - busca perceber os serviços de } \\
\text { informação como fenômeno de mediação vinculado as } \\
\text { diversas possibilidades funcionais do ambiente de } \\
\text { informação, como pessoal, acervo, serviços, uso das } \\
\text { tecnologias e as relações entre si para o efetivo } \\
\text { funcionamento de suas atividades; atenta para a } \\
\text { definição das funções do ambiente de informação e a } \\
\text { satisfação das necessidades de informação do usuário; } \\
\text { pensa o ambiente de informação como um todo e suas } \\
\text { partes de modo interdependente; prima pela noção de } \\
\text { integração, permanência e estabilidade; atenta de } \\
\text { forma vital para os processos de gestão, planejamento } \\
\text { e avaliação do ambiente de informação como fator de } \\
\text { funcionamento; prima pela satisfação das } \\
\text { necessidades de informação desde as mais básicas até } \\
\text { as mais complexas; busca constituir uma efetiva } \\
\text { prática dos sistemas de recuperação de informação e } \\
\text { suas funções para uso adequado e proveitoso do } \\
\text { usuário. }\end{array}$ & $\begin{array}{l}\text { Competências em informação } \\
\text { ocorre na perspectiva de que a } \\
\text { mediação da informação, através dos } \\
\text { serviços de informação, busca } \\
\text { incentivar formas de aprendizado, } \\
\text { domínio, construção do conhecimento e } \\
\text { tomadas de decisão em situações } \\
\text { específicas/imediatas } \\
\text { gerais/mediatas. }\end{array}$ \\
\hline $\begin{array}{l}\text { Crítica - preconiza os serviços de informação como } \\
\text { prática de mediação a partir da superação da ideia de } \\
\text { dominação ideológica e cultural, promovendo ao } \\
\text { usuário a oportunidade de participar do processo } \\
\text { mediacional e escolher o que pretende utilizar e } \\
\text { constituindo liberdade para apropriação da } \\
\text { informação, sendo necessário promover amplo acesso } \\
\text { à informação contemplando os chamados não- } \\
\text { usuários, pois o acesso à informação restrito em } \\
\text { ambientes de informação a uma minoria da população } \\
\text { engendra subsídios de dominação e monopólio } \\
\text { informacional. }\end{array}$ & $\begin{array}{l}\text { Produtos de informação - mediação e } \\
\text { serviços de informação preconizam a } \\
\text { elaboração de produtos que otimizem a } \\
\text { qualidade das práticas de mediação e } \\
\text { serviços de informação. Esses produtos } \\
\text { podem ser oriundos de serviços } \\
\text { diversos como referência, informação } \\
\text { utilitária, disseminação seletiva da } \\
\text { informação etc, bem como a } \\
\text { constituição dos produtos aprimora a } \\
\text { concretude prática dos serviços e da } \\
\text { mediação da informação. }\end{array}$ \\
\hline $\begin{array}{l}\text { Pragmático - envolve a mentalidade da mediação, via } \\
\text { serviços de informação, a partir de uma percepção }\end{array}$ & $\begin{array}{l}\text { Estudo de usuários - incide sobre uma } \\
\text { das principais práticas intervencionistas }\end{array}$ \\
\hline
\end{tabular}


pragmática de cunho social, artístico, gerencial, tecnológico e preservacionista que gere efeitos práticos, por um lado, nos ambientes de informação a partir da elaboração, por exemplo, de produtos de informação e, por outro lado, no cotidiano dos usuários como novas tomadas de decisão, geração de novos conhecimentos, novas formas de comunicação.

Construtivista - os construtos da mediação da informação necessitam do oferecimento de serviços de informação que incentivem estratégias para o letramento informacional dos usuários que corresponde ao processo de desenvolvimento de competências para localizar, selecionar, acessar, organizar, usar informação e gerar conhecimento, visando à tomada de decisão e à resolução de problemas; deve primar pelo incentivo a pesquisa, pois é um dos procedimentos mais eficientes e eficazes para a transformação de um conhecimento elementar para um conhecimento superior; incentivar o usuário a desenvolver seus próprios questionamentos e descobertas.

Sócio-interacionista - mediação e serviços de informação estão sintonizados no âmbito de aspectos históricos, culturais e interacionais no processo de produção da informação e do conhecimento que podem ser visualizados diante de: quais práticas e serviços podem (ou devem) ser oferecidos, com vistas a aprimorar e tornar o processo mediacional mais coletivo e plural; valorizar o usuário como sendo ponto central da mediação, pois a base das atividades mediacionais está naquilo que o usuário potencializa e em suas interações com o ambiente de informação, haja vista que o ambiente de informação deve não somente ser uma 'instituição falante', mas também uma 'instituição ouvinte' e aberta a novas ideias.

Fonte: Parcialmente adaptado de Carvalho (2016) e parcialmente elaborado pelos autores.

Diante do quadro apresentado, as relações entre mediação e serviços de informação se dão de forma fluida no contexto paradigmático, o qual opera como uma espécie de diretriz da prática informacional, e no contexto temático-aplicativo, que age como um conjunto de práticas de intervenção e interferências no desiderato informacional. que tornam os serviços de informação mais adequados à comunidade de usuários e a mediação da informação mais dialógica, interacionista e construída considerando o respeito às diferenças e a pluralidade de pensamentos, ideias e ações informacionais.

Tecnologias de informação - incide sobre a multiplicidade de suportes digitais/virtuais que permitam um alcance mais amplo aos usuários pelos serviços de informação pluralizando as formas de interlocução, intervenção e interferência da mediação da informação.

Gestão da informação - os serviços de informação devem ser geridos em seus diversos tipos, suportes e pessoal. A mediação da informação implícita ou explícita, custodial ou pós-custodial, técnica, pedagógica ou institucional dinamizam a gestão da informação conferindo sentido mais sólido e programático à realização dos serviços de informação. 
A mediação atua como um programa de ação, intervenção e interferência, e os serviços de informação se constituem como uma das principais atividades técnica, pedagógica, institucional e pragmática da mediação. A mediação auxilia no planejamento, programação e ampliação da envergadura aplicativa dos serviços de informação, enquanto os serviços de informação atestam o caráter aplicativo da mediação.

\section{Abordagens aplicativas da mediação da informação nos serviços de informação}

Os bibliotecários devem pressupor que suas ações mediarão o conhecimento entre os documentos e seus usuários. Nesta relação, as estratégias de organização do conhecimento contribuem para efetivar o acesso do usuário às informações de que precisa para apreender, transferir e transcender o conhecimento.

\subsection{Serviços que requerem mediação implícita}

A mediação implícita, embora não detenha a prerrogativa do contato direto com o usuário, é atividade relevante para estabelecer uma aproximação mais concreta entre o ambiente de informação e a comunidade de usuários. A mediação implícita se dá a partir dos seguintes fatores, a saber:

a) mediação como processo de estímulo interativo - envolve os mecanismos e ferramentas estruturados pelos ambientes de informação que auxiliam na interação indireta com o usuário. Por exemplo, uso das técnicas de representação (catalogação, classificação e indexação), uso de vocabulários controlados, elaboração do catálogo, estrutura tecnológica digital para posterior interação com o usuário através do sistema de informação, site, email, aplicativo, redes sociais etc. A estrutura técnica concebida pelo ambiente de informação, é um meio implícito de mediação e contribuem direta ou indiretamente para dinamizar as práticas de mediação explícita. Neste caso, a mediação como processo de estímulo interativo age de duas formas: a interação entre o ambiente de informação e a organização a qual está vinculado; e a interação entre a equipe de profissionais para possibilitar a estrutura técnica necessária para mediação implícita; 
b) mediação na organização do acervo - a organização/representação da informação envolve etapas, tais como: seleção do acervo (aproveitar o material que será utilizado; identificação (uso do carimbo da biblioteca para definir que aquele material é pertencente aquela instituição); registro (serve para saber quantos livros existe na biblioteca e para identificar o livro na hora de empréstimo, o que demanda o uso do carimbo e de um livro de registro ou tombo); o uso de um sistema de recuperação de informação ou software de gerenciamento do acervo (é fundamental para registrar o acervo de forma automática) e classificação (é útil para localizar um livro em uma coleção; retirar um livro para consulta com rapidez; devolver um livro à coleção com rapidez; inserir novo livro e outros materiais bibliográficos aos já existentes na coleção, sem que esses percam a sua ordem lógica). (PIMENTEL; BERNARDES; SANTANA, 2007). A mediação no contexto da organização pode ser considerada como implícita ou técnica e tem como principais legados: a salvaguarda de documentos, preservação da memória e armazenamento de conteúdos nas mais diversas formas de registro (bibliográfico, oral, iconográfico, audiovisual, entre outros), além do oferecimento de possibilidades para disseminação, recuperação e apropriação da informação. Neste sentido, todo ambiente de informação necessita da mediação implícita ou técnica no âmbito da organização para prover serviços elementares para a atuação dos ambientes de informação;

c) mediação no âmbito do uso das fontes de informação - é um complemento dos dois aspectos anteriores, visto que o processo de estímulo interativo aliado à organização com qualidade, dinamicidade e pluralidade documental-informacional preveem promoção em larga escala para o acesso e uso das fontes de informação pela comunidade de usuários. Isso significa que este tipo de mediação é de caráter implícito, mas também apresenta subsídios de mediação explícita por já estabelecer perspectivas de interação direta com o usuário, a partir das atividades de organização e disseminação da informação. $\mathrm{O}$ uso das fontes de informação envolve desde o estímulo ao uso de materiais bibliográficos convencionais como livros, artigos e revistas até materiais documentais diversos como literatura cinzenta, e-book, bases de dados e repositórios, periódicos, anais de eventos, sites especializados etc. e a constante disseminação junto à comunidade desse tipo de materiais elaborando produtos, quais seja, guias, cartilhas e manuais, elucidando aos usuários sobre os processos de utilização dos materiais. 
A mediação implícita da informação é um fenômeno que, embora seja considerado tradicional nos ambientes de informação, tomou grandes e novas proporções com o desenvolvimento tecnológico digital conquistando novas atribuições e aproximando-se mais da comunidade no sentido de constituir os usuários para além da presença física nos ambientes de informação, isto é, preconizando múltiplas possibilidades de acesso e uso das fontes de informação na perspectiva espaço-temporal, o que denota maior aproximação com os prospectos da mediação explícita da informação.

\subsection{Serviços que requerem mediação explícita}

a) mediação no serviço de referência - a relevância do trabalho de referência deve ser reconhecida pelos bibliotecários na orientação do usuário para utilização da biblioteca e fontes de informação. Esse seria um ato de mediação, o que representa o verdadeiro papel social desse profissional e também uma função educativa, que pode ser demonstrada pela forma como as pessoas aprendem por meio da informação e da comunicação. (SHERA, 1973). A biblioteca aspira mediar seu conteúdo com o usuário, e o serviço de referência pratica a estratégia da mediação por meio de: entrevista e do esclarecimento das questões do usuário, pela difusão da informação e educação do usuário. (VARELA; BARBOSA, 2012);

b) mediação no serviço de informação utilitária - esse serviço surge para suprir uma grande lacuna de ação das bibliotecas: as ações voltadas para as necessidades do dia-a-dia dos usuários. Muitos usuários vão às bibliotecas para empréstimo de livros, leituras individuais ou em grupo, e pesquisas. A mediação no âmbito do serviço de informação utilitária pode ser constituída a partir dos seguintes segmentos: saúde; cultura e lazer; utilidade pública; e trabalho. (SILVA; SILVA, 2012).

c) mediação via disseminação seletiva da informação (DSI) - reside na atividade de oferecer um serviço de informação notificador e filtrador, visando corresponder a uma demanda/expectativa/necessidade do usuário. Neste caso, a DSI é uma atividade mediacional que demanda um profissional especializado para fazer a filtragem dos conteúdos. A DSI se processa, conforme Amstel (2004), da seguinte forma: após a filtragem 
é feito o tratamento dessa informação (formatação, sintetização, metadados, etc.) e depois a distribuição. Mas essa distribuição é de acordo com o que o seu destinatário necessita (seletiva), e o serviço bem realizado, consegue aproveitar ao máximo ofeedback do usuário, ao mesmo tempo que maximiza a entrega de informações relevantes.

d) mediação nos serviços de informação de estímulo a cultura - a importância da prática da ação cultural nas unidades de informação, explica-se pela contribuição educativa que a mesma produz e seu caráter transformador na realidade social. A ação cultural não se limita somente a disponibilização dos bens culturais, deve possibilitar também a participação e a criação de novos bens culturais e conhecimentos. O bibliotecário deve proporcionar um ambiente para que o usuário participe, no sentido de opinar, formular e criar. (ROSA, 2009).

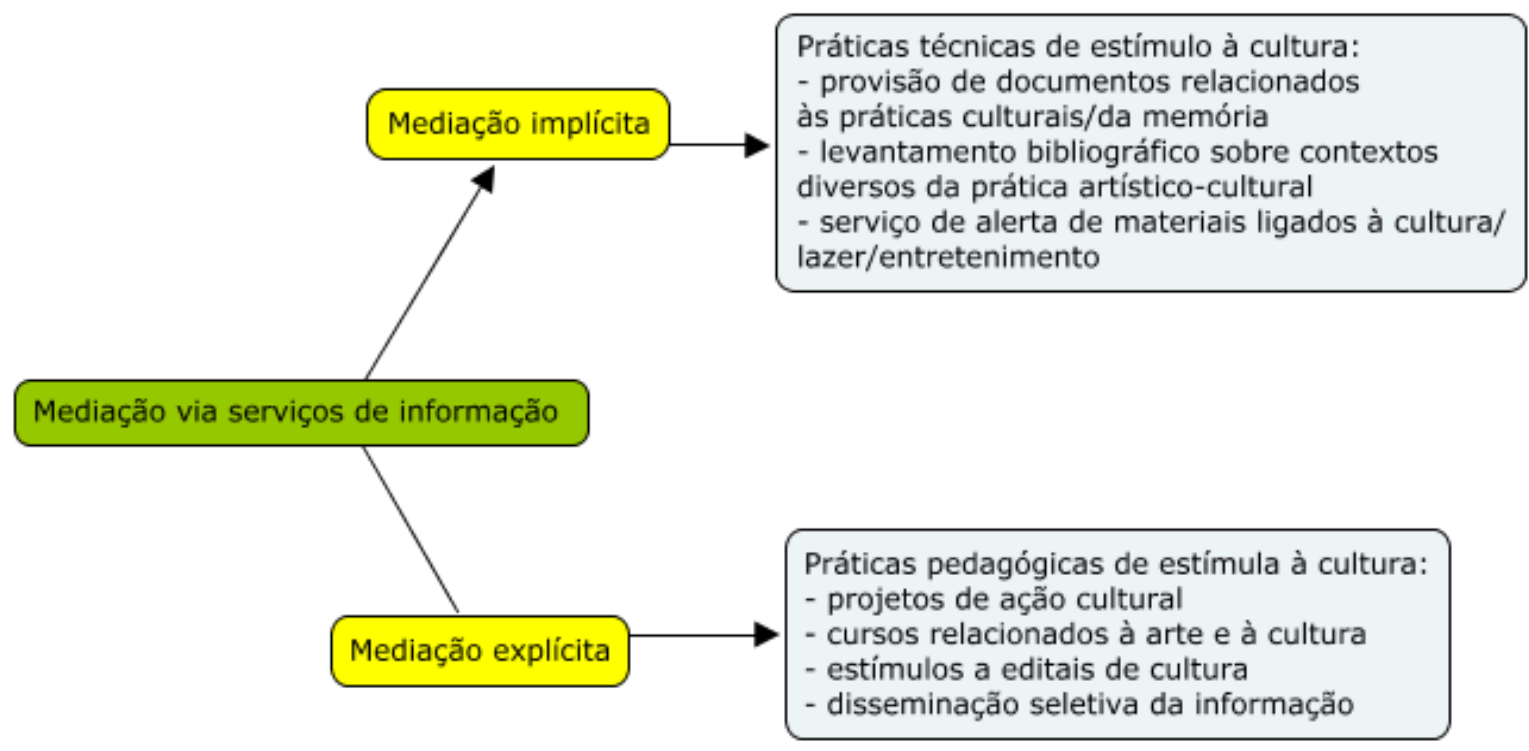

Figura 1 - Mediação nos serviços de informação de estímulo a cultura Fonte: Elaborado pelos autores (2015).

e) mediação para leitura - é comum remeter a mediação da leitura como processo de responsabilidade educativa. Todavia, é preciso considerar que a mediação é um ato de construção de sentido de vida. A escola/universidade não podem e nem devem ser as únicas mediadoras da leitura. Os mediadores são a família, professores, bibliotecários, amigos, escritores, pesquisadores, editores, críticos literários, jornalistas, livreiros, entre outros. 
(SILVA; SILVA, 2012). Como mediadores de leitura, os bibliotecários devem: buscar o aprendizado contínuo e a melhoria de suas qualificações e competências; envolver-se e colaborar com a crescente demanda evidenciada nos diversos segmentos da sociedade, a exemplo da escola e da biblioteca pública. (RASTELI; CAVALCANTE, 2013).

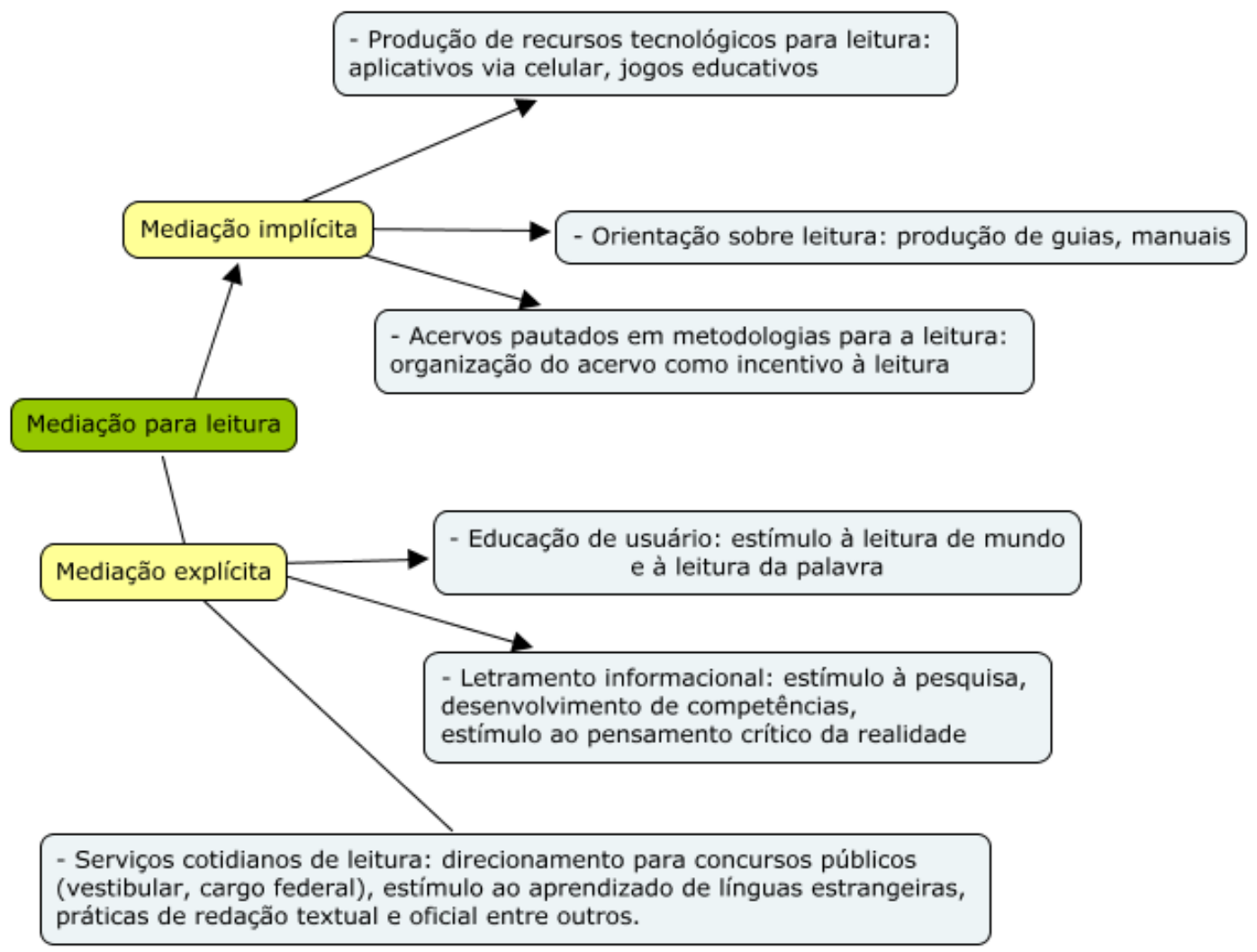

Figura 2 - Mediação para leitura

Fonte: Elaborado pelos autores (2015).

A mediação para a leitura, a partir do ambiente de informação, deve estimular o usuário a: interpretar o seu cotidiano, as suas condições e perspectivas de vida; pois uma leitura distante da realidade cotidiana pode se configurar como algo inibidor da construção de sentidos.

f) mediação no processo de pesquisa - envolve práticas técnicas, pedagógicas e institucionais para incentivar o aprendizado e a construção do conhecimento através de atividades, quais sejam: estímulo a atividade em equipe (coletividade entre os usuários; incentivar a autonomia do usuário na busca de materiais para o desenvolvimento da pesquisa; incentivo a elaboração de trabalhos acadêmico-científicos como projetos, artigos etc.; estímulo à construção de projetos científicos, institucionais (para a melhoria da InCID: R. Ci. Inf. e Doc., Ribeirão Preto, v. 8, n. 2, p. 106-123, set. 2017/fev. 2018. 
organização em que o ambiente de informação está inserido) e operacionais; dinamização do uso de materiais especializados como bases de dados, repositórios, periódicos e anais de eventos. Para tanto, é fundamental valorizar cotidianamente o uso das fontes de informação, serviço de referência, DSI, informação utilitária e uso de tecnologias digitais para o incentivo à pesquisa, denotando que a mediação no processo de pesquisa demanda um conjunto de práticas implícitas e, principalmente explícitas.

A mediação explícita traz à baila a ideia de um dos grandes desafios para os ambientes de informação nas últimas décadas, que é construir uma sólida atividade de cunho pedagógico e institucional, arregimentando estratégias e forças para ampliar as possibilidades de acesso à informação, tornando o ambiente mais democrático, plural e acessível no aparato espaço-temporal.

As mediações implícitas e explícitas determinam que o ambiente de informação, deve buscar a promoção do acesso à informação de maneira direta ou indireta, nos mais diversos territórios e temporalidades, transformando não-usuários e usuários potenciais em usuários efetivos, acessando as múltiplas práticas de mediação implícita e explícita desenvolvidas pelo ambiente de informação.

\section{Considerações finais}

Diante do exposto, foi possível observar as múltiplas práticas de mediação nos serviços de informação, considerando o serviço de referência, o serviço de informação utilitária, a mediação nos serviços de informação de estímulo à cultura, a mediação para a leitura e no processo de pesquisa. Pode-se inferir que a mediação nos serviços de informação se dá, sobretudo, pelos processos pragmáticos implícitos e explícitos, sendo pertinente correlacioná-los para compreender a dinâmica do serviço de informação e, em especial, para a formação de competência.

É preciso arregimentar metodologias e estratégias que promovam a mediação entre o significado dos recursos e serviços informacionais, seus usuários e visitantes, levando-os a um momento de reflexão mais profunda. Para isso, é preciso aplicar teorias, métodos e técnicas da Biblioteconomia e da CI, na concepção, planejamento, execução e funcionamento da biblioteca. 
Constata-se, neste estudo, que a relação entre mediação e serviços de informação produz perspectivas para os ambientes de informação, no sentido de estimular a apropriação da informação, competências em informação, produtos de informação, estudo de usuários, tecnologias de informação e gestão da informação.

Percebe-se ainda que há uma mutualidade aplicativa entre mediação e serviços de informação. A mediação é fundamental para o redimensionamento estratégico dos serviços em ambientes de informação, assim como os serviços de informação auxiliam no aprimoramento da mediação da informação. Logo, a mediação é um fenômeno programático de intervenção e interferências para uma comunidade, e os serviços de informação se constituem como um dos fatores determinantes para promoção da dinâmica mediacional.

As percepções de mediação implícita e explícita, custodial e pós-custodial e técnica, pedagógica e institucional inserem a ideia de que os serviços de informação, estruturados a partir de um programa de mediação de informação denotam maior possibilidade, consistência, e continuidade, pois tomam como base aspectos fundantes de cunho paradigmático, positivista, funcionalista, crítico, pragmático, construtivista e sócio interacionista, atestando que a mediação é uma diretriz estratégica que pensa, planeja, idealiza e aplica práticas informacionais, permitindo processos de apropriação, formação de competências, criação de produtos, construção de novos conhecimentos e tomadas de decisão para a comunidade de usuários.

Este estudo demonstra várias possibilidades de aplicação da mediação implícita e explícita, tanto para a fundamentação das pesquisas sobre mediação da informação na Ciência da Informação, quanto para práticas profissionais em ambientes de informação. Especialmente na mediação explícita, são marcantes as práticas dos múltiplos serviços de informação como referência (físico e virtual), informação utilitária, DSI, cultura, leitura e pesquisa para o desenvolvimento da mentalidade mediacional nos ambientes de informação. Portanto, as relações entre mediação e serviços de informação demonstram o amplo caráter técnico, pedagógico e institucional do campo da Ciência da Informação e das práticas profissionais nos ambientes de informação. 


\section{Referências}

AMSTEL, F. Van. Otimizando o fluxo de informações nas empresas. Webinsider, 01 nov. 2004. Disponível em: <http://webinsider.com.br/2004/11/01/otimizando-o-fluxo-de-informacoes-nasempresas/>. Acesso em: 01 nov. 2016.

ALMEIDA JÚNIOR, O. F. Mediação da informação e múltiplas linguagens. In: ENCONTRO NACIONAL DE PESQUISA EM CIÊNCIA DA INFORMAÇÃO, 9., São Paulo: ANCIB, 2008. Anais eletrônicos... São Paulo: ANCIB, 2008.

Mediação da informação e múltiplas linguagens. Pesquisa Brasileira em Ciência da Informação, Brasília, v. 2, n. 1, p. 89-103, jan./dez. 2009.

ALMEIDA, M. A. A produção social do conhecimento na sociedade da informação. Informação \& Sociedade: estudos, v. 19, n. 1, p. 11-18, 2009.

CARVALHO, J. Tópicos em Biblioteconomia e Ciência da Informação: epistemologia, política e educação. Rio de Janeiro: Agência Biblioo, 2016.

KUHLTHAU, C. C. Seeking meaning: a process approach to library and information services. Norwood: Ablex, 1993.

LAMIZET, B. La médiation culturelle. Paris: L’Harmattan, 1999.

MALHEIRO, A. Mediações e mediadores em Ciência da Informação. PRISMA.COM, n. 9, 2009.

PIMENTEL, G.; BERNARDES, L.; SANTANA, M. Biblioteca escolar. Brasília: Universidade de Brasília, 2007.

RASTELI, A.; CAVALCANTE, L. U. A competência em informação e o bibliotecário mediador da leitura em biblioteca pública. Encontros Bibli: revista eletrônica de biblioteconomia e ciência da informação, v. 18, n. 36, p. 157-180, jan./abr., 2013.

ROSA, A. J. S. A prática da ação cultural em bibliotecas. Revista ACB: Biblioteconomia em Santa Catarina, Florianópolis, v. 14, n. 2, p.372-381, jul/dez. 2009.

ROZADOS, H. B. F. Indicadores como ferramenta para gestão de serviços de informação tecnológica. 2004. 220f. Tese. (Doutorado em Ciência da Informação) - Faculdade de Biblioteconomia e Comunicação, Universidade Federal do Rio Grande do Sul, Porto Alegre, 2004.

SANTOS, H.; REZENDE, F. Formação, mediação e prática pedagógica do tutor orientador em ambientes virtuais construtivistas de aprendizagem. Tecnologia Educacional, v. 31, n. 157/158, p.19-29, abr./set. 2002. 
SHERA, J. Toward a theory of librarianship and information science. Ciência da Informação, v. 2, n. 2, p. 87-97, 1973.

SILVA, J. L. C. Percepções conceituais sobre mediação da informação. Informação. InCID: Revista de Ciência da Informação e Documentação, Ribeirão Preto, v. 6, n. 1, p. 93-108, mar./ago. 2015.

.; SILVA, A. S. R. A mediação da informação como prática pedagógica no contexto da biblioteca escolar: algumas considerações. Biblioteca Escolar em Revista, Ribeirão Preto, v. 1, n. 2, p. 1-30, 2012.

VARELA, A. V. Informação e autonomia: a mediação segundo Feuerstein. São Paulo: SENAC, 2007, v. 1.368p.

.; BARBOSA, M. L. A. The complexity of finding information in collaborative information systems: cognitive needs. In: CURRÁS, E.; ROMERO, N. L. (Ed.). Systems science and collaborative information systems: theories, practices and new research. Hershey: IGI Global, 2012. p. 87-120.

.; _ _ _ FARIAS, M. G. G. Mediação em múltiplas abordagens. Informação \&

Informação, Londrina, v. 19, p. 138-170, 2014.

Artigo submetido em: 07 nov. 2016

Artigo aceito em: 03 jul. 2017 